\title{
Mechanism of Electrical Enhancement of Efficacy of Antibiotics in Killing Biofilm Bacteria
}

\author{
J. WILLIAM COSTERTON, ${ }^{1 *}$ BRIAN ELLIS, ${ }^{1}$ KAN LAM, ${ }^{1}$ FRANK JOHNSON, ${ }^{2}$ \\ AND ANTOINE E. KHOURY ${ }^{3}$ \\ Center for Biofilm Engineering Montana State University, Bozeman, Montana, ${ }^{1}$ and Institute of Medical Engineering, \\ University of Ottawa, Ottawa, ${ }^{2}$ and Hospital for Sick Children, University of Toronto, Toronto, ${ }^{3}$ Canada
}

Received 23 May 1994/Returned for modification 8 July 1994/Accepted 30 September 1994

\begin{abstract}
The bioelectric effect, in which electric fields are used to enhance the efficacy of biocides and antibiotics in killing biofilm bacteria, has been shown to reduce the very high concentrations of these antibacterial agents needed to kill biofilm bacteria to levels very close to those needed to kill planktonic (floating) bacteria of the same species. In this report, we show that biofilm bacteria are readily killed by an antibiotic on all areas of the active electrodes and on the surfaces of conductive elements that lie within the electric field but do not themselves function as electrodes. Considerations of electrode geometry indicate that very low $\left(<100 \mu \mathrm{A} / \mathrm{cm}^{2}\right)$ current densities may be effective in this electrical enhancement of antibiotic efficacy against biofilm bacteria, and flow experiments indicate that this bioelectric effect does not appear to depend entirely on the possible local electrochemical generation of antibacterial molecules or ions. These data are expected to facilitate the use of the bioelectric effect in the prevention and treatment of device-related bacterial infections that are caused by bacteria that grow in biofilms and thereby frustrate antibiotic chemotherapy.
\end{abstract}

Work in many laboratories $(16,17,32)$, including our own $(3,12,33)$, has clearly established that biofilm bacteria are resistant to antibiotics and biocides at levels 500 to 5,000 times higher than those needed to kill planktonic cells of the same species. The mechanism of this inherent resistance of glycocalyx-enclosed biofilm bacteria to antimicrobial agents is not conclusively established but appears to depend on both diffusion limitation (25) and physiological properties associated with low growth rates $(8,9,16,17)$ in biofilm populations. Direct examination of the surfaces of medical devices that have become the foci of device-related bacterial infections shows that these pathogens grow in well-developed adherent biofilms (12), and clinical experience (21) indicates that these chronic infections are highly refractory to antibiotic therapy. Consequently, device-related bacterial infections are aggressively treated with combinations of antibiotics $(2,27)$, but in many cases, the biofilm-colonized device must still be removed to facilitate the resolution of these infections $(21,37)$.

An increasing number of laboratories have begun to examine the effects of electric fields and current densities on biological systems $(1,5,15,19,28,31,34,35,38,41)$, mainly because of interest in the electroporation and electrofusion processes that are very useful in genetic research (31). This body of work has shown that electric fields and currents can be used for electroporation and electrofusion (31), electroosmosis, iontophoresis $(6,13-15)$, and the electroinsertion of specific proteins (30). During this work, it has been noted that electric fields and currents can influence the organization of biological membranes $(10,28,31,35,40,42)$ and membrane analogs $(1,18)$, metabolic and developmental processes within both prokaryotic and eukaryotic cells $(19,24,34,38,42)$, and possibly even the shape of the cell (36), cell behavior (41), and the dimensions of the bacterial glycocalyx (4). Most of these studies have used high-intensity fields and currents, in the

* Corresponding author. Mailing address: Center for Biofilm Engineering, Montana State University, Bozeman, MT 59717-0398. Phone: (406) 994-1960. Fax: (406) 994-6098. kilovolt-per-centimeter range, but a significant number $(5,13$, $15,24,36)$ have also focused on the effects of low-intensity fields and currents on biological systems for which significant effects have been documented, especially embryonic systems (34).

We have reported that low-intensity electric fields (field strength of 1.5 to $20 \mathrm{~V} / \mathrm{cm}$ and current densities of $15 \mu \mathrm{A} / \mathrm{cm}^{2}$ to $2.1 \mathrm{~mA} / \mathrm{cm}^{2}$ ) can completely override the inherent resistance of biofilm bacteria to biocides (7) and antibiotics (26). This bioelectric effect reduces the concentrations of these antibacterial agents needed to kill biofilm bacteria to 1.5 to 4.0 times those needed to kill planktonic cells of the same species. The present study was undertaken to examine the mechanism of this bioelectric effect, with the working hypothesis that the electric field aids the penetration of the antibacterial agents through the biofilm by a form of electrophoresis that may be assisted by the electrochemical generation of agents that enhance the efficacy of these agents.

\section{MATERIALS AND METHODS}

Bacterial strains. A strain (UR-21) of Pseudomonas aeruginosa obtained from a patient with a chronic urinary tract infection was used in these experiments because of the facility with which it formed thick biofilms. Aliquots were stored at $-70^{\circ} \mathrm{C}$, on brain heart infusion agar, and fresh aliquots were used to start each experiment. The MIC for this strain was 1.0 mg/liter.

Flow cell. The development of a three-electrode flow cell (Fig. 1) allowed us to extend our study to ascertain if the bioelectric effect was applicable to all electrode surfaces and to inert nonconductive (or conductive) materials placed between the electrodes. The two exterior stainless steel (type 316) electrodes (E1 and E3) were connected together to act as the anode with E2 (type 316) as the cathode for $64 \mathrm{~s}$, and then the current was reversed so that E1 and E3 acted as the cathode while E2 became the anode. Both stainless steel (type 316) inserts (I1 and I2) were placed between the electrodes in the electrical field and treated the same way as the electrodes 

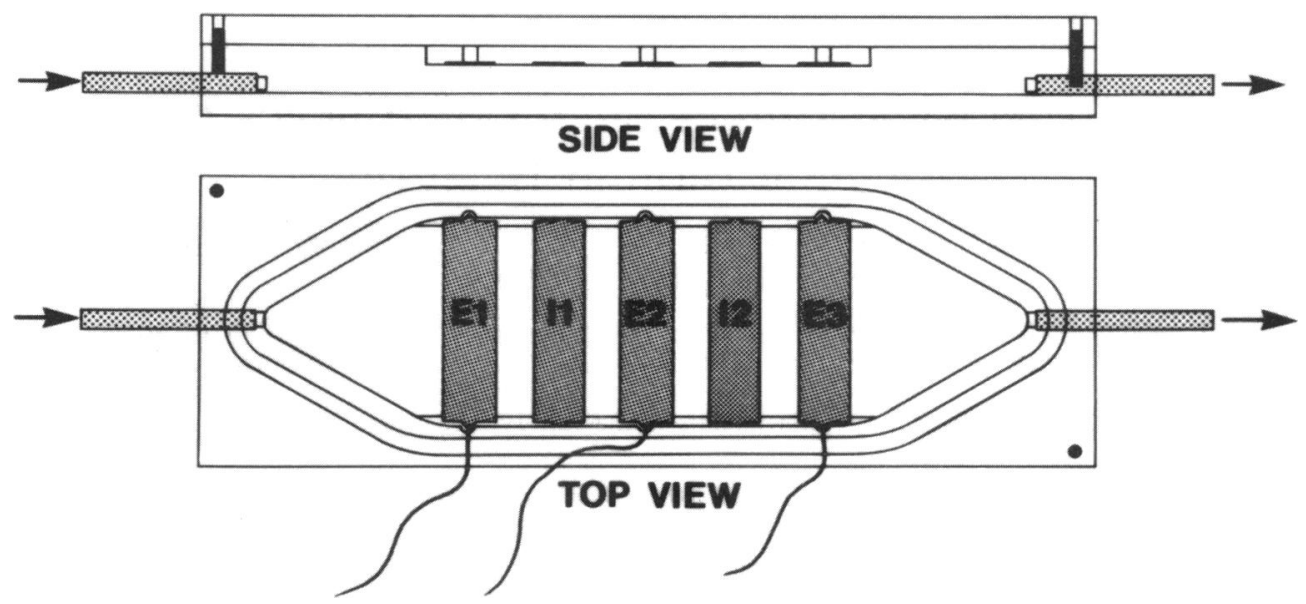

FIG. 1. Diagrammatic representation of the in vitro flow cell device showing the design of the Perspex flow chamber and the five type 316 stainless steel elements that compose the electrodes and the inserts. E1 and E3 are both connected to one pole of the power source and constitute one electrode, while E2 is connected to the opposite pole and constitutes the other electrode. I1 and I2 are not connected to the power source, and they constitute inserts within the system.

regarding microscopy and viable cell counts. The electrodes were connected to a direct current (DC) generator whose voltage output was adjustable up to $10 \mathrm{~V}$, and the current was variable up to $50 \mathrm{~mA}$. The current polarity was alternated every $64 \mathrm{~s}$ to help prevent the accretion of ions on the stainless steel surfaces.

Biofilm generation. Adherent, glycocalyx-enclosed biofilm populations were generated on the type 316 stainless steel $(0.08 \% \mathrm{C}, 2.00 \% \mathrm{Mn}, 0.045 \% \mathrm{P}, 0.03 \% \mathrm{~S}, 1.00 \% \mathrm{Si}, 16.00$ to $18.00 \% \mathrm{Cr}, 10.00$ to $14.00 \% \mathrm{Ni}, 2.00$ to $3.00 \% \mathrm{Mo}$; remaining percentage was $\mathrm{Fe}$ ) elements of the flow cell. The flow cell experiments involving $P$. aeruginosa utilized the chemically defined simple salts medium M-56 [30.6 mM Na $2 \mathrm{HPO}_{4}, 19.8$ $\mathrm{mM} \mathrm{KH} \mathrm{PO}_{4}, 7.57 \mathrm{mM}\left(\mathrm{NH}_{4}\right)_{2} \mathrm{SO}_{4}, 10.0 \mathrm{mg}$ of $\mathrm{MgSO}_{4} \cdot 7 \mathrm{H}_{2} \mathrm{O}$ per liter, $1.00 \mathrm{mg}$ of $\mathrm{Ca}\left(\mathrm{NO}_{3}\right)_{2} \cdot 4 \mathrm{H}_{2} \mathrm{O}$ per liter, $1.84 \mathrm{mg}$ of $\mathrm{FeSO}_{4} \cdot 7 \mathrm{H}_{2} \mathrm{O}$ per liter], which was supplemented with glucose $(0.9 \%$ [ $\mathrm{vol} / \mathrm{vol}])$ and L-leucine $(0.066 \mathrm{~g} /$ liter $)$. The resistivity of this medium was $3.86 \mathrm{mS} / \mathrm{cm}$. Two liters of this medium was inoculated ( $2 \%$ [vol/vol]) with a culture of strain UR-21 which had been grown in M-56 supplemented with $1 \%$ brain heart infusion broth for $16 \mathrm{~h}$ in an orbital shaker $\left(125 \mathrm{rpm}\right.$ at $\left.37^{\circ} \mathrm{C}\right)$, and the medium was pumped through the flow cell at a rate of $60 \mathrm{ml} / \mathrm{h}$ with a peristaltic pump (Cole-Parmer, Chicago, Ill.). After $24 \mathrm{~h}$ of colonization, the flow was stopped and the culture fluid was replaced (time $=0$ ) with fresh sterile medium with or without tobramycin sulfate (Sigma Chemical Co.) at a concentration of $5.0 \mathrm{mg} /$ liter, because the planktonic MIC for the urinary tract infection isolate used in these studies was 1.0 $\mathrm{mg} /$ liter. The flow was then reestablished at a rate of $60 \mathrm{ml} / \mathrm{h}$.

Sampling protocol. After 24 or $48 \mathrm{~h}$ of exposure to sterile medium with or without tobramycin and with or without the application of the DC electric field, the flow cell was dismantled. The electrodes and inserts were cut in half and the halves were processed separately for scanning electron microscopy and viable cell counts. For scanning electron microscopy, the electrodes were fixed in 5\% glutaraldehyde (in $0.1 \mathrm{M}$ cacodylate buffer, $\mathrm{pH} 7.0$ ) overnight at $4^{\circ} \mathrm{C}$, washed five times in cacodylate buffer, and air dried. The samples were coated with $\mathrm{Au}-\mathrm{Pd}$ in a sputter coater and viewed with a Hitachi S450 electron microscope. For the determination of viable-cell counts, the biofilm on the other half of each electrode and insert was dispersed into $5 \mathrm{ml}$ of phosphate-buffered saline
(PBS) by aseptic scraping and by the application of low-power sonic energy (model 2200; Branson Ultrasonics Corporation) as outlined in previous publications $(2,3,33,39)$. Each suspension was vortexed and serially diluted in PBS prior to being plated in duplicate for the counting of CFUs. The brain heart infusion agar plates were incubated for $18 \mathrm{~h}$ at $37^{\circ} \mathrm{C}$ prior to counting.

\section{RESULTS}

The degree of biofilm formation by cells of $P$. aeruginosa on the stainless steel elements of the flow cell was seen to be much higher (Fig. 2) than that produced by the same organisms in our previous experiments $(7,26)$ using stainless steel studs in the modified Robbins device, and the number of sessile organisms increased still further in untreated control preparations (Fig. 2) during these 48-h experiments. Electrical treatment alone for $24 \mathrm{~h}$ produced a 500 -fold decrease in the number of viable cells on the stainless steel elements of the flow cell, including the electrically passive inserts, but the number of viable cells in these biofilms returned to pretreatment levels during a further 24-h exposure to the electric field. Antibiotic treatment alone produced a gradual 100 -fold decrease in the number of viable cells in the biofilms on the stainless steel elements of the flow cell, but $5 \times 10^{5}$ cells per $\mathrm{cm}^{2}$ remained alive following this 48 -h exposure. Treatment of these established $P$. aeruginosa biofilms with 5.0 times the MIC of tobramycin in the presence of the electric field produced an almost complete kill $\left(<10^{2}\right.$ viable cells per $\left.\mathrm{cm}^{2}\right)$ of these sessile cells in $48 \mathrm{~h}$ (Fig. 2). This level of kill of biofilm bacteria was found on the surfaces of all five steel elements (Fig. 1) of the flow cell (three electrodes and two electrically unconnected inserts). The field strength of this electric field was calculated to be $5 \mathrm{~V} / \mathrm{cm}$, and the current was measured at $\pm 15 \mathrm{~mA}$ at the time of polarity reversal and at 6.0 to $6.7 \mathrm{~mA}$ in the stable period between alternations, giving a calculated average current density of $1.7 \mathrm{~mA} / \mathrm{cm}^{2}$ in this geometrically complex system. Because the biofilm was recovered from all areas of the stainless steel elements of these flow cells, for analysis for viable organisms, we can state that virtually no biofilm bacteria remained alive after $48 \mathrm{~h}$ of exposure to an antibiotic within this electric field. 


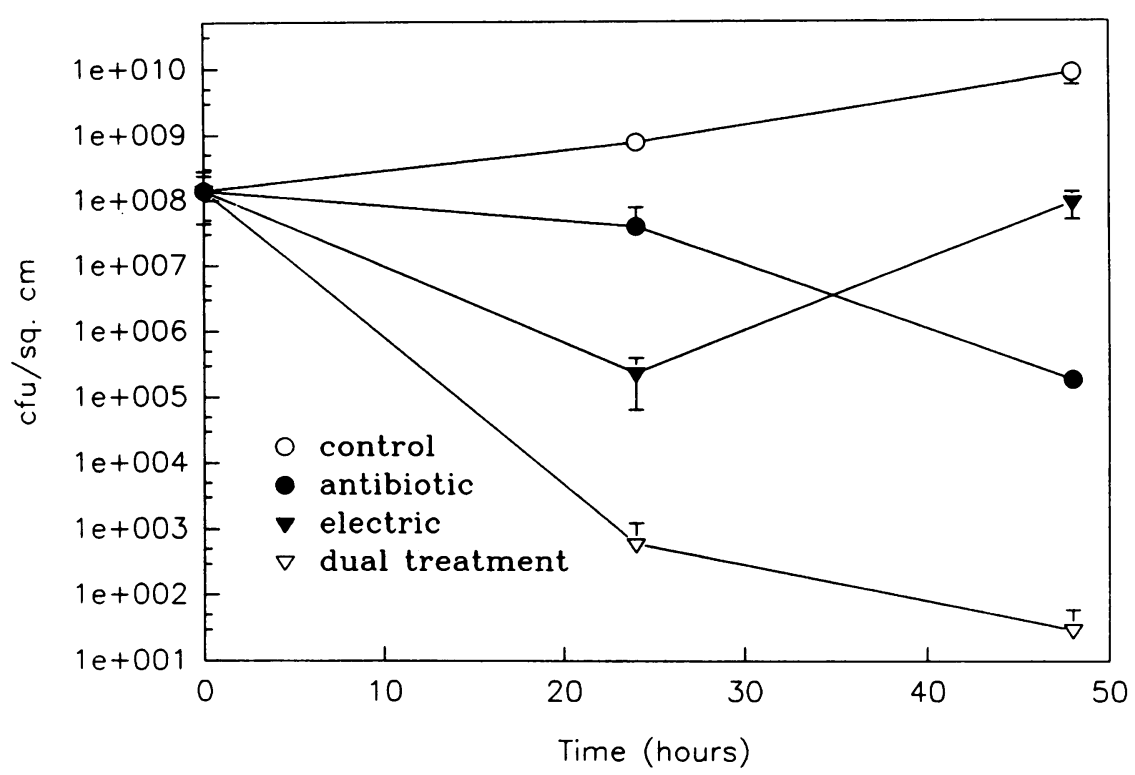

FIG. 2. Graphic representation of the average CFU of viable biofilm cells of $P$. aeruginosa per square centimeter on all five steel elements of the flow device in untreated-control experiments and following exposure to 5.0 times the MIC of tobramycin in the presence and absence of the electric field. Virtually all of the biofilm cells were killed by 5.0 times the MIC of tobramycin in the presence of the electric field, while significant numbers of viable cells remained following exposure to the antibiotic alone or to the electric current alone and the sessile population increased in the absence of any treatment.

The portions of the outer electrodes (Fig. 1) that did not face the center electrode would experience only very low current densities, and the actual values of current densities over the surfaces of these electrodes is very difficult to estimate. For this reason, the average current density was estimated by dividing the total current by the total area. The average current density at the central electrode will necessarily be twice that of the outer electrodes. It is of interest to calculate that the current density at the outer electrodes will diminish towards the extreme edges and will reach values of $<100 \mu \mathrm{A} / \mathrm{cm}^{2}$ in these regions that, nonetheless, experienced almost total killing of biofilm bacteria.

We examined the $P$. aeruginosa biofilms on the various steel elements of the flow cell (by scanning electron microscopy) before and after treatments to promote killing of these sessile organisms by the bioelectric effect. Following $24 \mathrm{~h}$ of colonization to produce biofilms with a cell density of $10^{8} \mathrm{CFU} / \mathrm{cm}^{2}$, and before any experimental protocols were initiated, all steel surfaces were covered by thick biofilms of slime-enclosed bacterial cells (Fig. 3A). After $48 \mathrm{~h}$ of treatment with the electric field alone, the biofilm in Fig. 3B, which still contained large numbers of viable bacteria (Fig. 2), was structurally intact and structurally similar to the untreated biofilm seen in Fig. 3A. Biofilms that had been treated for $48 \mathrm{~h}$ with the antibiotic alone also contained large numbers of viable bacteria and resembled the untreated biofilm in all structural parameters (Fig. 3C). However, treatment with tobramycin at $5.0 \mathrm{mg} / \mathrm{liter}$ (5.0 times the MIC) in the presence of the electric field killed virtually all of the biofilm bacteria on all five steel elements of the flow cell (Fig. 2), and examination of the electrode surfaces showed that the biofilm had been at least partially removed (Fig. 3D, area I) on the edges of the electrodes nearest the electrode of opposite polarity. Residual biofilm (Fig. 3D, area II) and intact bacterial cells (Fig. 3E) were clearly seen in areas of the electrodes and in areas of the inserts that were not subjected to maximum field strengths by close juxtaposition with the opposite electrode, but the cells remaining on the denuded areas were severely distorted and obviously cavitated (Fig. 3F).

We have noted that biofilm bacteria are not killed by the application of an electric field alone $(7,26)$ (Fig. 2) and that biofilm bacteria on electrically passive inserts within electric fields (Fig. 1) are killed by low concentrations of an antibiotic, which suggests that the penetration of the biofilm by the antibiotic is enhanced by an electric field that is not, in itself, damaging to biofilm bacteria. However, we felt that we should still examine the possibility that these sessile cells were being killed by the combined effect of the antibiotic and a molecule or ion (perhaps chlorine, peroxide, or superoxide) that is generated electrochemically at the electrode surface. To examine this possibility we undertook the series of experiments outlined in Table 1 . Flow cells were colonized to produce biofilms on all five elements, as in the experiments whose results are summarized in Fig. 2, but the surviving bacteria were quantitated on each element individually in order to detect possible downstream effects caused by ion generation. In the untreated-control experiments no statistically significant differences in the numbers of viable biofilm bacteria were seen among the five elements (three electrodes and two inserts). Similarly, there were no significant differences among the elements when the flow cell was treated with the antibiotic alone (5.0 times the MIC of tobramycin), but the numbers on all elements were significantly different from the numbers in the untreated-control experiment, and a general 1-log reduction in the number of viable biofilm bacteria was recorded. When the electrodes of the flow cell were energized in the absence of the antibiotic, the number of surviving biofilm bacteria on the inserts was not significantly different from the number on the five elements of the untreated control, and the number on the energized electrodes was reduced less than 1 order of magnitude. We should note that any ions that had been electrochemically generated in this electric treatment had 

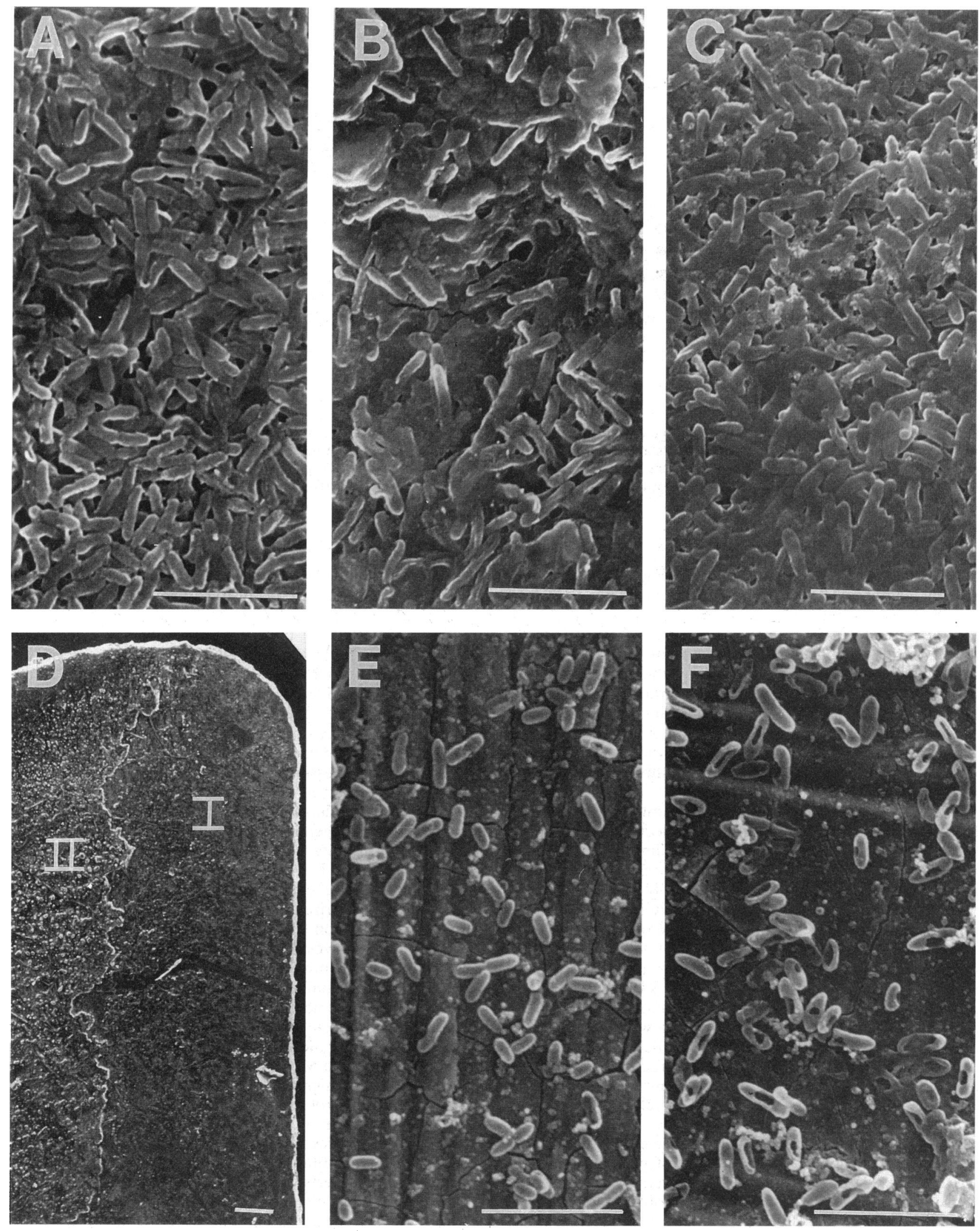
TABLE 1. Killing of biofilm bacteria on individual elements of the flow cell by various treatments ${ }^{a}$

\begin{tabular}{|c|c|c|c|c|c|}
\hline \multirow{2}{*}{ Treatment } & \multicolumn{5}{|c|}{ Avg CFU $/ \mathrm{cm}^{2}$ on element: } \\
\hline & E1 & I1 & E2 & 12 & E3 \\
\hline None (control) & $5.22 \times 10^{8}$ & $3.45 \times 10^{8}$ & $2.35 \times 10^{9}$ & $3.95 \times 10^{8}$ & $4.18 \times 10^{8}$ \\
\hline Antibiotic & $1.96 \times 10^{7}$ & $2.29 \times 10^{7}$ & $2.35 \times 10^{7}$ & $1.51 \times 10^{7}$ & $3.74 \times 10^{7}$ \\
\hline Electric & $8.07 \times 10^{7}$ & $2.17 \times 10^{8}$ & $6.54 \times 10^{7}$ & $2.25 \times 10^{8}$ & $3.02 \times 10^{7}$ \\
\hline Electric + antibiotic & $1.65 \times 10^{2}$ & $1.55 \times 10^{3}$ & $6.71 \times 10^{2}$ & $8.00 \times 10^{2}$ & $5.90 \times 10^{2}$ \\
\hline Downstream & $1.76 \times 10^{6}$ & $6.76 \times 10^{5}$ & $1.16 \times 10^{6}$ & $1.28 \times 10^{6}$ & $2.19 \times 10^{6}$ \\
\hline
\end{tabular}

${ }^{a}$ All elements were treated for $48 \mathrm{~h}$, and all experiments were repeated four times except the downstream test, which was repeated five times. Statistics were done on a Macintosh computer by using the SuperANOVA program for one-way analysis of variance and multiple comparison of means by the Tukey-Kramer test $(\alpha=0.05)$. The analysis was performed on the log transformed data (i.e., CFU per square centimeter $=\log (\mathrm{CFU}$ per square centimeter +1$)$.

very little effect on the viability of biofilm bacteria anywhere in the flow cell in the absence of the antibiotic. When the biofilm bacteria in the flow cell were exposed to $5 \mu \mathrm{g}$ of tobramycin per $\mathrm{ml}$ in the presence of the DC field, the numbers of surviving biofilm bacteria were reduced to the same extent on both the electrodes and the inserts; these reductions were highly significant as determined by comparison of the numbers with those after any other treatment (control, antibiotic alone, or electrical field alone). We conducted downstream-antibiotic experiments in which a separate five-element flow cell was attached by tubing downstream from a flow cell being treated with an antibiotic in the presence of a DC field. We speculated that any electrically generated antibacterial ions would be carried to the downstream flow cell, with the antibiotic, and would enhance the killing of biofilm cells in the downstream flow cell. The data concerning the survival of biofilm bacteria in this downstream flow cell (Table 1) show a significant but minor (1-log) reduction compared with data on exposure to the antibiotic alone (Table 1), and we conclude that the effects of any electrochemically generated species were minor.

Next we reasoned that any electrochemically generated ions that might enhance the efficacy of an antibiotic against biofilm bacteria would be carried downstream within a single flow cell, so the upstream side of E1 (Fig. 1) would accumulate only very low concentrations. The downstream elements (I2 and E3) would, by the same process, be exposed to higher concentrations of this putative ion. The data concerning the killing of biofilm bacteria in electric and electric-antibiotic treatments in Table 1 indicate no asymmetry in the killing of these sessile bacteria on the upstream and downstream elements of the flow cell. To examine this hypothesis still further, we conducted an experiment to examine the extent of killing of biofilm bacteria on individual elements of a flow cell in which only electrodes E1 and E2 were connected to the electrical generator. Element E3 must be considered outside the DC field. In this experiment, the flow cells were colonized for $24 \mathrm{~h}$ and then treated for $24 \mathrm{~h}$ with $5 \mu \mathrm{g}$ of tobramycin per $\mathrm{ml}$, with only the first two electrodes connected to the power supply $(5 \mathrm{~V}, 64$-s reversal of polarity). The biofilm kill data clearly indicate that these adherent organisms are killed more rapidly on elements E1 and E2 and significantly more slowly on elements I1 and I2 in this 24-h period. Elements E1, I1, E2, I2, and E3 had $4.92 \times$ $10^{4}, 2.24 \times 10^{5}, 3.87 \times 10^{4}, 2.44 \times 10^{5}$, and $3.43 \times 10^{6}$ $\mathrm{CFU} / \mathrm{cm}^{2}$, respectively; data are the averages of five experiments whose results were analyzed by the SuperANOVA program as for Table 1 . There is no significant difference between the first four elements in the group; however, E3, which was electrically passive in this experiment, had a number of adherent organisms significantly different from that of any other single element within the group. These data indicate that any electrochemically generated ions have only a minor effect on the enhancement of the killing of biofilm bacteria by antibiotics within a DC field.

\section{DISCUSSION}

Relative to biofilm bacteria, planktonic bacteria can be exquisitely susceptible to biocides and antibiotics, if they lack resistance mechanisms and contain the appropriate target molecules, because they float or swim in the bulk fluid and are readily accessed by these antibacterial agents. Biofilm bacteria are often found to be involved in industrial problems (39) or in medical infections $(21,33)$ that have resisted clearance by biocides or antibiotics, and many reports $(8,16,17,21,33,39)$ have documented their inherent resistance to these agents, even at concentrations 500 to 5,000 times those needed to kill planktonic cells. This inherent resistance of biofilm bacteria to antibiotics is now widely accepted $(12,21)$ as the basis for the remarkably refractory response of device-related and other chronic bacterial infections to antibiotic chemotherapy. A vigorous debate concerning the mechanism of this inherent resistance of biofilm bacteria to antibiotics currently rages, and it now seems clear that the resistance is a function of both altered growth rate and physiology $(8,9,16,17,32)$ and of diffusion barriers provided by the biofilm matrix $(12,21,25)$.

Against the background of this inherent resistance of biofilm bacteria to antibacterial agents, it is significant that we have recently shown that the efficacy of biocides (7) and antibiotics (26) in killing biofilm bacteria can be radically enhanced if these agents are used within a low-intensity DC electric field.

FIG. 3. Scanning electron micrographs of the surfaces of various biofilm-colonized steel elements of the flow cell illustrated in Fig. 1. (A) Surface of the biofilm in an untreated device at $0 \mathrm{~h}$ (i.e., after $24 \mathrm{~h}$ of colonization), when this biofilm contained large numbers of living bacteria (Fig. 2). (B and C) Surfaces of the biofilms on electrode (E2) surfaces when the devices had been treated with the electric field alone (B) or with the antibiotic (tobramycin) alone (C); both biofilms contained substantial numbers of viable bacteria. (D) Surface of an electrode (E1) from a device that had been treated with tobramycin (5.0 times the MIC) in the presence of the electric field; we noted the partial removal of the biofilm from the edge of this electrode (area I) nearest to electrode E2 and its retention in the area (area II) more distant from the electrode of opposite polarity (E2). There were no living bacteria on the surface of this electrode, but visually intact bacterial cells were seen (E) in area II, while severely disrupted and cavitated cells were seen $(F)$ on the denuded surface of area I. Bars $=5 \mu \mathrm{m}$. 
This bioelectric effect has been shown to operate in the killing of biofilm cells of several species of gram-negative and grampositive bacteria, and of fungi, by several different chemical classes of biocides and antibiotics $(7,26)$. Because only a DC electric field produces the bioelectric effect, and because the electric field does not by itself kill biofilm bacteria, we have evolved a working hypothesis that this effect depends largely on electrophoretic forces that allow the antimicrobial agents to overcome diffusion barriers that would otherwise limit their access to their targets within bacterial and fungal cells. Similar DC currents have been used clinically to drive chemotherapeutic molecules into solid tumors (29) and antibiotic molecules into the inner ear (11) and other tissues (5).

However, there are many ways in which physical forces affect biochemical processes in biological systems. Bacterial cells depend, as do all living cells, on physical phenomena such as membrane potentials (10) for their basic metabolic activity, and it is reasonable to expect that delicate cellular electrical equilibria may be disturbed by the imposition of an external electric field. It has been shown that external fields can affect the $\alpha$-helix content $(28,42)$ and orientation $(10)$ of membrane proteins in eukaryotic cells and the electrophoretic mobilities of bacterial membrane proteins $(10,20)$. Electric fields can even be used to effect the electroinsertion of specific proteins into the membranes of living cells (30). These molecular perturbations of important membrane components may affect the organization of membranes $(10,28,31,35,40,42)$, and we expect that these structural changes would influence the permeability of membranes vis-à-vis antibiotics and biocides (22, 23). Profound membrane perturbations, caused by very intense electric fields, are routinely used in electroporation to facilitate exogenous-DNA exchange in genetic experiments (31).

Davis and his colleagues (13-15) have reported that planktonic cells of $E$. coli, $P$. aeruginosa, Proteus mirabilis, and Candida albicans can be killed by electric fields and current densities similar to ours but without the use of antibiotics. Davis et al. $(13,15)$ attributed the killing of these planktonic cells to iontophoresis, in which the accretion of metal ions on or in the bacterial cell could be responsible for this bactericidal effect, or the effect could be caused by the electrical generation of chloride species (14) with biocidal properties. The lowstrength electric fields used in the present study did not, by themselves, kill biofilm bacteria, and we suggest that ion binding by the exopolysaccharide matrix of the biofilm (12) may protect these sessile cells from iontophoretic killing.

In the present study of the bioelectric effect, we have set out to examine the extent to which electrochemical effects at the electrode surface contribute to the enhanced efficacy of antibacterial agents. Any putative electrochemical mechanism must only contribute to the bioelectric effect because the electric fields used in these experiments do not, in themselves, kill biofilm bacteria. To examine this phenomenon in a rational manner, we designed the flow cell illustrated in Fig. 1 so that the stainless steel electrodes (E1, E2, and E3) would constitute a symmetrical field and the electrically passive steel inserts (I1 and I2) would be placed symmetrically within that field. Our data clearly show that biofilm bacteria are killed on all steel surfaces within the flow cell in the presence of an antibiotic, including those bacteria that were not on electrodes and those that were adherent to the outside edges of the outer electrodes that would be subjected to only very low current densities. Biofilm cells were seen to be cavitated, and biofilms were partially removed on the inside edges of electrodes facing the oppositely charged electrodes, where the current density would be highest, while no obvious cell damage or biofilm disturbance was seen in areas that would be subjected to lower current densities. However, virtually all biofilm bacteria were dead on all of the steel surfaces of the flow cell after $48 \mathrm{~h}$ of exposure to 5.0 times the MIC of tobramycin within the electric field. Because very low levels of current density were effective, and because nonelectrode surfaces were affected, we feel that electrochemical effects were not of paramount importance in the bioelectric effect in this system. If an electrochemically generated molecule or ion were an essential contributor to the bioelectric effect, one would expect that it might be carried some distance downstream in an actively flowing system. Our flow experiments show that the bioelectric effect is seen on the element (I2) immediately downstream of an active electrode in an asymmetrically electrified flow cell but that it is seen only to a minor extent on the next element (E3) downstream or in a separate downstream flow cell connected to the electrically active flow cell. In light of these data, electrically assisted electrophoresis remains our preferred explanation of the bioelectric effect with some suggestion of an electrochemically generated agent that enhances killing by antibiotics.

In our plans to use the bioelectric effect to prevent and to treat device-related bacterial infections, we are encouraged by these observations that relatively weak electric fields enhance the efficacy of antibiotics in killing biofilm bacteria even on surfaces that are not, in themselves, electrodes. We are further encouraged by evidence that, at the field strengths used in this study, the effect is not largely dependent on potentially damaging electrochemically generated ionic or molecular species.

\section{ACKNOWLEDGMENTS}

We are deeply grateful for financial support from the Natural Sciences and Engineering Research Council of Canada (IRC-0097240) and the Medical Research Council of Canada (MA-9533).

\section{REFERENCES}

1. Amory, D. E., and J. E. Dufey. 1985. Model for the electrolytic environment and electrostatic properties of biomembranes. J. Bioenerg. Biomembr. 17:151-174.

2. Anwar, H., and J. W. Costerton. 1990. Enhanced activity of combination of tobramycin and piperacillin for eradication of sessile biofilm cells of Pseudomonas aeruginosa. Antimicrob. Agents Chemother. 34:1666-1671.

3. Anwar, H., M. K. Dasgupta, and J. W. Costerton. 1990. Testing the susceptibility of bacteria in biofilms to antibacterial agents. Antimicrob. Agents Chemother. 34:2043-2046.

4. Applegate, D. H., and J. D. Bryers. 1990. Effects of carbon and oxygen limitations and calcium concentrations on biofilm removal processes. Biotechnol. Bioeng. 37:17-25.

5. Belehradek, J., S. Orlowski, L. H. Ramirez, G. Pron, B. Poddevin, and C. M. Mir. 1994. Electropermeabilization of cells in tissues assessed by the qualitative and quantitative electroloading of bleomycin. Biochim. Biophys. Acta 1190:155-163.

6. Berger, T. J., J. A. Spadaro, S. E. Chapin, and R. O. Becker. 1976. Electrically generated silver ions: quantitative effects on bacterial and mammalian cells. Antimicrob. Agents Chemother. 9:357-358.

7. Blenkinsopp, S. A., A. E. Khoury, and J. W. Costerton. 1992. Electrical enhancement of biocide efficacy against Pseudomonas aeruginosa biofilms. Appl. Environ. Microbiol. 58:3770-3773.

8. Brown, M. R. W., D. G. Allison, and P. Gilbert. 1988. Resistance of bacterial biofilms to antibiotics: a growth-related effect? J. Antimicrob. Chemother. 22:777-783.

9. Brown, M. R. W., P. J. Collier, and P. Gilbert. 1990. Influence of growth rate on susceptibility to antimicrobial agents: modification of the cell envelope and batch and continuous culture studies. Antimicrob. Agents Chemother. 34:1623-1628.

10. Cevc, G. 1990. Membrane electrostatics. Biochim. Biophys. Acta 1031:311-381.

11. Chang, I. W., Y. B. Cho, and S. C. Lim. 1989. Iontophoretic application of cefotiam hydrochloride into inner ear through round window membrane. Chonnam J. Med. Sci. 2:141-144. 
12. Costerton, J. W., K.-J. Cheng, G. G. Geesey, T. I. Ladd, J. C. Nickel, M. Dasgupta, and T. J. Marrie. 1987. Bacterial biofilms in nature and disease. Annu. Rev. Microbiol. 41:435-464.

13. Davis, C. P., N. Wagle, M. D. Anderson, and M. M. Warren. 1991. Bacterial and fungal killing by iontophoresis with long-lived electrodes. Antimicrob. Agents Chemother. 35:2131-2134.

14. Davis, C. P., N. Wagle, M. D. Anderson, and M. M. Warren. 1992. Iontophoresis generates an antimicrobial effect that remains after iontophoresis ceases. Antimicrob. Agents Chemother. 36:25522555.

15. Davis, C. P., S. Weinberg, M. D. Anderson, G. M. Rao, and M. M. Warren. 1989. Effects of microamperage, medium, and bacterial concentration on iontophoretic killing of bacteria in fluid. Antimicrob. Agents Chemother. 33:442-447.

16. Eng, R. H. K., F. T. Padberg, S. M. Smith, E. N. Tan, and C. E. Cherubin. 1991. Bactericidal effects of antibiotics on slowly growing and nongrowing bacteria. Antimicrob. Agents Chemother. 35:1824-1828.

17. Gilbert, P., M. R. W. Brown, and P. J. Collier. 1990. Influence of growth rate on susceptibility to antimicrobial agents: biofilms, cell cycle, dormancy, and stringent response. Antimicrob. Agents Chemother. 34:1865-1868.

18. Glaser, R. W., S. L. Leikin, L. V. Chernomordik, V. F. Pastushenko, and A. J. Sokirko. 1988. Reversible electrical breakdown of lipid bilayers: formation and evolution of pores. Biochim. Biophys. Acta 940:275-287.

19. Goodman, R., C. A. L. Bassett, and A. S. Henderson. 1983. Pulsing electromagnetic fields induce cellular transcription. Science 220: 1283-1285.

20. Gowrishankar, T. R., R. C. Lee, P. K. Patel, and D. E. Golan. 1991. Cell shape dependent rectification of surface receptor transport in sinusoidal a.c. electric fields, p. 32. Abstr. 11th Annu. Meet. Bioelectric Repair and Growth Society 1991.

21. Gristina, A. G., J. J. Dobbins, B. Giammara, J. C. Lewis, and W. C. DeVries. 1988. Biomaterial centered sepsis and the total artificial heart: microbial adhesion vs. tissue integration. JAMA 259:870877.

22. Hancock, R. E. W. 1984. Alterations in outer membrane permeability. Annu. Rev. Microbiol. 38:237-264.

23. Hancock, R. E. W. 1991. Bacterial outer membranes: evolving concepts. ASM News 57:175-182.

24. Harrington, D. B., R. Meyer, Jr., and R. M. Klein. 1975. Effects of small amounts of electric current at the cellular level. Ann. N. Y. Acad. Sci. 247:300-305.

25. Hoyle, B. D., J. Alcantara, and J. W. Costerton. 1992. Pseudomonas aeruginosa biofilm as a diffusion barrier to piperacillin. Antimicrob. Agents Chemother. 36:2054-2056.

26. Khoury, A. E., K. Lam, B. D. Ellis, and J. W. Costerton. 1992. Prevention and control of bacterial infections associated with medical devices. Am. Soc. Artif. Intern. Org. J. 38:M174-M178.

27. Levy, S. B., J. P. Burke, and C. K. Wallace (ed.). 1987. Antibiotic use and antibiotic resistance worldwide. Report of a study sponsored by the Fogarty International Center of the National Institutes of Health, 1983-1986. Rev. Infect. Dis. 9:S231-S316.

28. McLaughlin, S. 1989. The electrostatic properties of membranes. Annu. Rev. Biophys. Biophys. Chem. 18:113-136.

29. Miklavcic, D., G. Sersa, S. Novakovic, and S. Rebersek. 1990. Tumor bioelectric potential and its possible exploitation for tumor growth retardation. J. Bioelectr. 9(2):133-150.

30. Mouneimne, Y., P.-F. Tosi, R. Barhoumi, and C. Nicolau. 1991. Electroinsertion of xeno proteins in red blood cell membranes yields a long lived protein carrier in circulation. Biochim. Biophys. Acta 1066:83-89.

31. Neumann, E., A. E. Sowers, and C. A. Jordan (ed.). 1989. Electroporation and electrofusion in cell biology. Plenum Press, New York.

32. Nichols, W. W., M. J. Evans, M. P. E. Slack, and H. L. Walmsley. 1989. The penetration of antibiotics into aggregates of mucoid and non-mucoid Pseudomonas aeruginosa. J. Gen. Microbiol. 135: 1291-1303.

33. Nickel, J. C., I. Ruseska, J. B. Wright, and J. W. Costerton. 1985. Tobramycin resistance of Pseudomonas aeruginosa cells growing as a biofilm on urinary catheter material. Antimicrob. Agents Chemother. 27:619-624.

34. Nuccitelli, R. 1990. Vibrating probe for studies of ion transport, p. 273-310. In J. K. Foskett and S. Grinstein (ed.), Noninvasive techniques in cell biology. Wiley-Liss, New York.

35. Pethica, B. A., and D. G. Hall. 1982. Electric field effects on membranes. J. Colloid Interface Sci. 85:41-51.

36. Rajnicek, A. M., C. D. McCaig, and N. A. R. Gow. 1994. Electric fields induce curved growth of Enterobacter cloacae, Escherichia coli, and Bacillus subtilis cells: implications for mechanisms of galvanotropism and bacterial growth. J. Bacteriol. 176:702-713.

37. Root, R. K., D. D. Trunkey, and M. A. Sande (ed.). 1987. New surgical and medical approaches in infectious diseases. Churchill Livingstone, New York.

38. Rowley, B. A., J. M. McKenna, and G. R. Chase. 1975. The influence of electrical current on an infecting microorganism in wounds. Ann. N. Y. Acad. Sci. 247:543-551.

39. Ruseska, I., J. Robbins, J. W. Costerton, and E. S. Lashen. 1982. Biocide testing against corrosion-causing oil field bacteria helps control plugging. Oil Gas J. 8:253-264.

40. Sabelnikov, A. G., E. S. Cymbalyuk, G. Gongadze, and V. L. Borovyagin. 1991. Escherichia coli membranes during electrotransformation: an electron microscope study. Biochim. Biophys. Acta 1066:22-28.

41. Shi, W., M. J. Lentz, and J. Adler. 1993. Behavioral responses of Escherichia coli to changes in temperature caused by electric shock. J. Bacteriol. 175:5785-5790.

42. Tsong, T. Y. 1990. Electrical modulation of membrane proteins: enforced conformational oscillations and biological energy. Annu. Rev. Biophys. Biophys. Chem. 19:83-106. 